\title{
ASPECTOS SOCIAIS DA MOTIVAÇÃO PARA LEITURA ENTRE JOVENS E ADULTOS ${ }^{1}$
}

\author{
Jorge Teles (UFF)
}

\section{RESUMO}

Este artigo objetiva analisar dois aspectos sociais da prática de leitura entre jovens e adultos no Brasil contemporâneo, a partir dos argumentos elencados como motivação para essa prática pelos sujeitos entrevistados na pesquisa Retratos da Leitura no Brasil. Diante da persistência histórica do analfabetismo e do baixo nível de leitura no país, cabe atentar criticamente para as motivações que levam jovens e adultos a lerem, buscando entender a dinâmica social deste fenômeno. No mundo contemporâneo, não ter domínio da leitura se tornou um mecanismo estrutural de exclusão de direitos. A análise do acesso à cultura escrita se torna, assim, uma forma de avaliar o sistema de garantia de direitos da sociedade brasileira.

Palavras-chave: Práticas de leitura. Motivação para ler. Educação de jovens e adultos.

\section{ABSTRACT \\ SOCIAL ASPECTS OF MOTIVATION FOR READING AMONG YOUTH AND ADULTS}

This article aims to analyze two social aspects of reading practice among youngsters and adults in contemporary Brazil, based on the arguments listed as motivation for this practice by the subjects interviewed in the Portraits of Reading research in Brazil. Given the historical persistence of illiteracy and the low level of reading in the country, it is critical to criticize the motivations that lead young people and adults to read, trying to understand the social dynamics of this phenomenon. In the contemporary world, not mastering reading has become a structural mechanism of exclusion of rights. The analysis of access to written culture thus becomes a way of evaluating the rights guarantee system of Brazilian society.

Keywords: Reading practices. Motivation to read. Youth and adult education.

1 Este artigo é parte de uma pesquisa maior sobre dimensões sociais das motivações para práticas de leitura de jovens e adultos no Brasil.

* Doutor em Educação pela Universidade Federal Fluminense. Atua no Centro de Pesquisa e Editoração da Fundação Biblioteca Nacional. E-mail: jl.teles@yahoo.com.br 


\section{RESUMEN}

\section{ASPECTOS SOCIALES DE LA MOTIVACIÓN PARA LECTURA ENTRE JÓVENES Y ADULTOS}

Este artículo objetiva analizar dos aspectos sociales de la práctica de lectura entre jóvenes y adultos en el Brasil contemporáneo, a partir de los argumentos enumerados como motivación para esa práctica por los sujetos entrevistados en la investigación Retratos de la Lectura en Brasil. Ante la persistencia histórica del analfabetismo y del bajo nivel de lectura en el país, cabe atentar críticamente para las motivaciones que llevan a jóvenes y adultos a leer, buscando entender la dinámica social de este fenómeno. En el mundo contemporáneo, no tener dominio de la lectura se ha convertido en un mecanismo estructural de exclusión de derechos. El análisis del acceso a la cultura escrita se convierte así en una forma de evaluar el sistema de garantía de derechos de la sociedad brasileña.

Palabras clave: Prácticas de lectura. Motivación para leer. Educación de jóvenes y adultos.

\section{Um problema resiliente}

A leitura tem sido uma questão muito discutida no Brasil há muito tempo. O alto grau de analfabetismo de sua população tem sido denunciado desde o império. $O$ país tem passado por diversas políticas educacionais e culturais desde o século XIX, porém a questão ainda não foi solucionada (FERRARO, 1985 e 2009; FERRARO e KREIDLOW, 2004). A afirmativa de que os brasileiros leem pouco tem sido repetida por décadas, sem, todavia, uma resposta à altura. $\mathrm{O}$ caso inclusive ganha visibilidade de tempos em tempos. Campanhas de alfabetização são montadas em tom emergencial, visando a "erradicação" do analfabetismo. Por vezes lembram-se dos adultos, mas, na maioria das ocasiões, pretende-se focar nas novas gerações, sob o pretexto de construir um "novo futuro", ou assumindo a perspectiva de que a geração adulta já "se perdeu", do ponto de vista da leitura.

As pesquisas apontam para a persistência do analfabetismo no Brasil. Ainda que decrescendo, as taxas continuam altas para o nível de oferta educacional alcançado pelo país - fato que se confirma normalmente comparando os indicadores educacionais brasileiros com aqueles apresentados por outros países. Além disto, os números absolutos são muito altos. Isto quer dizer que persiste um número muito elevado de sujeitos jovens e adultos que ainda não são considerados alfabetizados, colocando o Brasil dentre os oito países do mundo com o maior número de analfabetos com 15 anos ou mais de idade.

Segundo dados coletados pelo Instituto Brasileiro de Geografia e Estatística (IBGE), a taxa de analfabetismo entre jovens e adultos chega a 9,6\% no Brasil em 2010. Isto representa 13,9 milhões de pessoas com 15 anos ou mais de idade. Ferraro (2009) demonstra que esta taxa tem se movido muito lentamente nos últimos anos, persistindo grande diferença entre os totais de pessoas analfabetas por grupos etários em 2010. Apesar da redução na taxa de analfabetismo nas últimas décadas, ainda há um gran- 
de número de pessoas que estão excluídas de seu direito à educação, apontando para a importância de se elaborar políticas públicas de alfabetização para pessoas com 15 anos ou mais de idade.

Outras dimensões também apontam para as disparidades nas taxas de analfabetismo, contemplando as questões de raça, por exemplo (idem). O analfabetismo é maior entre negros, demonstrando que historicamente a abolição da escravatura não significou uma alteração radical da posição do negro na sociedade brasileira. Apesar de "livre" de submissão ao trabalho escravo, os negros ainda são discriminados socialmente, preteridos no acesso à escolarização e mantidos subalternizados por outros mecanismos que não mais os grilhões e a senzala. $\mathrm{O}$ acesso à leitura e à escrita também se constitui enquanto forma de exclusão social.

Quando se observa as taxas em termos territoriais, percebe-se que a distribuição não é uniforme, com concentração nas regiões Norte e Nordeste. Conforme apontam Ferraro e Kreidlow (2004), existem muitas disparidades entre as Unidades da Federação. O Estado com maior nível de analfabetismo é Alagoas, enquanto o menor é o Distrito Federal, representando uma diferença de quase 20 pontos percentuais entre eles. Em termos gerais, existem 12 Estados com taxas acima da média nacional. Estes Estados estão concentrados nas Regiões Norte e Nordeste do país, apontando para uma concentração territorial das disparidades.

Quando se pensa em território, apesar do Brasil ser considerado um país urbanizado, a parcela de população que vive em meio rural ainda é representativa. Deste total, uma grande quantidade ainda permanece no analfabetismo absoluto. No meio rural ainda há territórios onde mais de dois terços da população adulta não sabe ler nem escrever.
Em relação à questão de gênero, a abordagem geral esconde alguns problemas específicos. Por exemplo, o analfabetismo permanece alto entre as mulheres mais velhas, normalmente negras e habitantes de área rural, principalmente no Nordeste e no Norte. Isto demonstra que a situação da mulher avançou para umas, mas atualmente ainda há violação do direito à educação e à cultura para muitas delas.

As discrepâncias nessas dimensões consideradas se tornam mais patentes quando se observa a questão pelo ângulo municipal. Ainda havia 1.304 municípios com taxas de analfabetismo entre jovens e adultos iguais ou superiores a 25\% em 2010, segundo o IBGE. Esta abertura dos dados também torna evidente a existência de bolsões de analfabetismo mesmo em Estados com baixo grau médio de analfabetismo. Por exemplo, a cidade de São Paulo, com seus altos indicadores educacionais, tem o maior número de jovens e adultos analfabetos do Brasil.

$\mathrm{O}$ número de analfabetos funcionais é muito elevado no país, segundo o IBGE. Quando se observa a evolução das taxas de analfabetismoseabsoluto e funcional, percebe-se que ocorre um deslocamento da população de uma para a outra. Isto significa que, ao longo dos anos, o fenômeno do analfabetismo foi ganhando outra configuração, mas permaneceu com sua intensidade total muito representativa em todo este tempo.

\section{As práticas de leitura}

Recentemente, as preocupações com a leitura literária impulsionaram a realização da pesquisa Retratos da Leitura no Brasil (AMORIM, 2008; FAILLA, 2012, 2016). Esta pesquisa visa identificar o comportamento dos brasileiros em termos de leitura de livros e, mais especificamente, sobre frequência dessa leitura. Ela considera leitor 
aquela pessoa que declarou que "leu, inteiro ou em partes, pelo menos 1 livro nos últimos 3 meses”. Em 2015, 56\% da população brasileira se declarou leitora.

Quando se abre a resposta sobre o que lê por tipo de material, há um destaque para jornais e revistas. Dentre os livros, os didáticos sobressaem. Cabe também frisar a frequência dos textos escolares e de trabalho. Portanto, pode-se inferir que a leitura está muito relacionada com atividades escolares e profissionais. Somando-se ao realce dado à motivação religiosa, começa-se a delinear melhor as bases do que aparece como "gosto pela leitura”. Cabe aprofundar a análise, para entender melhor o peso desses mecanismos escolares, trabalhistas e religiosos nas motivaçõespara a prática de leitura.

Se forem considerados os avanços tecnológicos e analisados mais pormenorizadamente os usos do tempo livre, percebe-se que quem lê também está envolvido com o meio digital em proporção muito maior que o não-leitor: Usa a Internet (60\% dos leitores usam sempre contra $32 \%$ dos não-leitores); Usa WhatsApp (53\% dos leitores usam sempre contra 30\% dos não-leitores); Usa Facebook, Twitter ou Instagram (44\% dos leitores usam sempre contra $24 \%$ dos não -leitores); Joga games ou videogames (15\% dos leitores jogam sempre contra 9\% dos não-leitores).

Dentre os que responderam que não liam, 28\% disseram que não o faziam porque "não gostam de ler", mas $9 \%$ responderam "Porque tem dificuldades para ler" e 20\% assumiram que "Não sabem ler". Se forem somadas com outras respostas que podem estar ocultando a dificuldade de leitura ou não alfabetização, tais como "Porque não tem paciência para ler" e "Porque se sente muito cansado para ler", ou mesmo as questões de dizer que não gosta ou não tem tempo, pode-se perceber o impacto do analfabetismo sobre a prática de leitura.

A pesquisa também perguntou se a pessoa tinha alguma dificuldade para ler: $67 \%$ respondeu que sim. Este fenômeno não está relacionado apenas ao analfabetismo absoluto, mas também aponta para os desdobramentos do analfabetismo funcional e para os modos como as gerações são formadas nas escolas e nos espaços não-formais de educação.

Esta pesquisa traz informações sobre as motivações para ler declaradas pelo público entrevistado. Dentre as respostas dadas, a categoria que mais se destacou foi "Gosto", com 25\% (FAILLA, 2016). Seria a leitura uma questão de "gosto"? Como se constrói socialmente o "gosto pela leitura"? Quais os impactos das dimensões sociais sobre a formação desses "gostos"? Neste artigo, compreende-se a leitura como uma prática social $^{2}$. A discussão sobre práticas é problematizada a partir dos conceitos de agência e estrutura. Tomando a primeira como a capacidade do indivíduo de tomar decisões por si próprio e a segunda como as influências externas e internas (externas internalizadas) que atuam sobre essa capacidade de tomar decisões. Neste contexto, destaca-se o debate sobre habitus na teoria sociológica referenciada em Bourdieu(1983, 2007, 2008, 2012; BOURDIEU e PASSERON, 2008, 2013; SETTON, 2002; WACQUANT, 2007). Por habitus se entende:

2 Entendendo "prática social" como atividades e comportamentos exercidos com certa regularidade em um grupo de indivíduos; são formas de fazer, de falar, de se comportar em conformidade com normas e regras explícitas ou implícitas de determinado grupo, compondo certo ordenamento da vida deste grupo - entendendo vida como as ações de ser e estar no mundo. Estas práticas são concretas, ou seja, podem ser observadas. Como apresentam padronização, regularidade e reprodutibilidade, podem ser tipificadas. 
(...) um sistema de disposições duráveis e transponíveis que, integrando todas as experiências passadas, funciona a cada momento como uma matriz de percepções, de apreciações e de ações - e torna possível a realização de tarefas infinitamente diferenciadas, graças às transferências analógicas de esquemas (...) (BOURDIEU, 1983, p. 65).

Para enriquecer este debate, será acrescido o conceito de "motivação". De acordo com Takaloo e Ahmadi (2017, p. 11), a motivação pode ser compreendida como uma força propulsora que atua sobre ou dentro de um organismo para estabelecer e gerenciar o seu comportamento. Estes autores apontam para a relação importante entre motivação e compreensão leitora. A discussão sobre as motivações será aprofundada, explorando as diferenciações entre o que seria impulsionado pela própria pessoa e o que viria de indução externa (RYAN and DECI, 2000).

Explorar o que é leitura para jovens e adultos envolve entender como os sujeitos lidam com a leitura em seu cotidiano e como a experiência escolar influencia as práticas de leitura para além do período escolar obrigatório. Por exemplo, dentre as motivações para leitura, não se pode esquecer que esta pode funcionar como uma ferramenta para alteração da posição social do sujeito. Neste sentido, há de se compreender estas práticas dentro da dinâmica do campo da leitura (BOURDIEU, 1983, 2014; WACQUANT, 2005). Os grupos sociais, em sua luta por manutenção do status quo, também produzem e reproduzem compreensões sobre determinadas práticas de leitura. As disputas sobre o que seria um leitor, um bom leitor, uma pessoa letrada não são apenas semânticas, mas refletem disputas sociais por manutenção ou tensionamentos por mudanças nos papéis indivi- duais nas estruturas sociais - não apenas economicamente falando, mas também de poder, prestígio e conhecimento ${ }^{3}$.

O campo da leitura não está apenas baseado em divisão por grupos sociais. Intragrupos também há disputas. Há diferentes interesses em jogo, quando se fala de leitura. As práticas de leitura não se dão no etéreo. Elas têm uma concretude. Há de se ter material para leitura. Os materiais considerados como "de leitura" e aceitos nos meios educacionais e sociais pressupõem um papel social da leitura e determinadas motivações para ler. Existem tensionamentos para classificação do que é leitura, e há grupos que disputam esta classificação. Por exemplo, muito da literatura sobre leitura está voltada para crianças. Muitos já desacreditam que pode ser mudada uma postura de um adulto em relação à leitura. Esta visão está baseada em argumentos de "hábito" e de "gosto", em uma concepção evolutiva do ser humano onde a mudança tem idade para acontecer, em termos de práticas sociais.

\section{Dimensões sociais e práticas de leitura}

A pesquisa Retratos da Leitura no Brasil (FAILLA, 2016) colhe informações sobre o comportamento leitor baseado em questões de gênero, geracionais e educacionais. Esta pesquisa não capta informações sobre as relações raciais e seu impacto sobre este comportamento leitor. Entendendo estas limitações, buscou-se maior compreensão sobre as relações entre as práticas sociais de leitura e as razões para tal apontada pelos entrevista-

$3 \quad$ As diferentes formas que os capitais são obtidos e acumulados definem formas de apropriação de saber, poder, prestígio e riqueza, as quais contribuem decisivamente para manutenção de determinada forma de composição dos papéis e lugares sociais dos grupos e dos sujeitos. 
dos, tendo como pano de fundo os conceitos de capitais cultural ${ }^{4}$ e social ${ }^{5}$ de Bourdieu (2012; BOURDIEU e PASSERON, 2008, 2013).A reprodução desse capital social através da troca e da manutenção de relações tem como objetivo consciente ou inconsciente manter e aperfeiçoar os limites do grupo e as vantagens de seus integrantes, sejam elas materiais ou simbólicas. A busca de aquisição e maior acúmulo de capitais cultural e social fazem parte do jogo da sociedade à qual a pessoa pertence, mas também aos campos sociais pelos quais ela transita. Estas interações entre regras maiores e regulamentos mais específicos produzem tipos de interação com a leitura que fazem variar as razões e desdobramentos de sua prática.
As questões geracional e educacional foram as principais variáveis destacadas pela pesquisa em foco. Elas estão na base das forças que diferenciam as formações das práticas de leitura, mas também existem as questões econômicas, relacionadas às dinâmicas de classe. Estas dimensões afetam decisivamente a relação dos sujeitos com a cultura escrita (KALMAN, 2003a e 2003b).

As principais motivações apontadas como resposta para a pergunta "Qual é a principal razão para o(a) sr(a) ler?” foram: gosto; atualização cultural ou conhecimento geral; distração; crescimento pessoal; motivos religiosos; exigência escolar ou da faculdade; e, atualização profissional ou exigência do trabalho (FAILLA, 2016).

Figura 1 - Principal motivação para ler um livro.

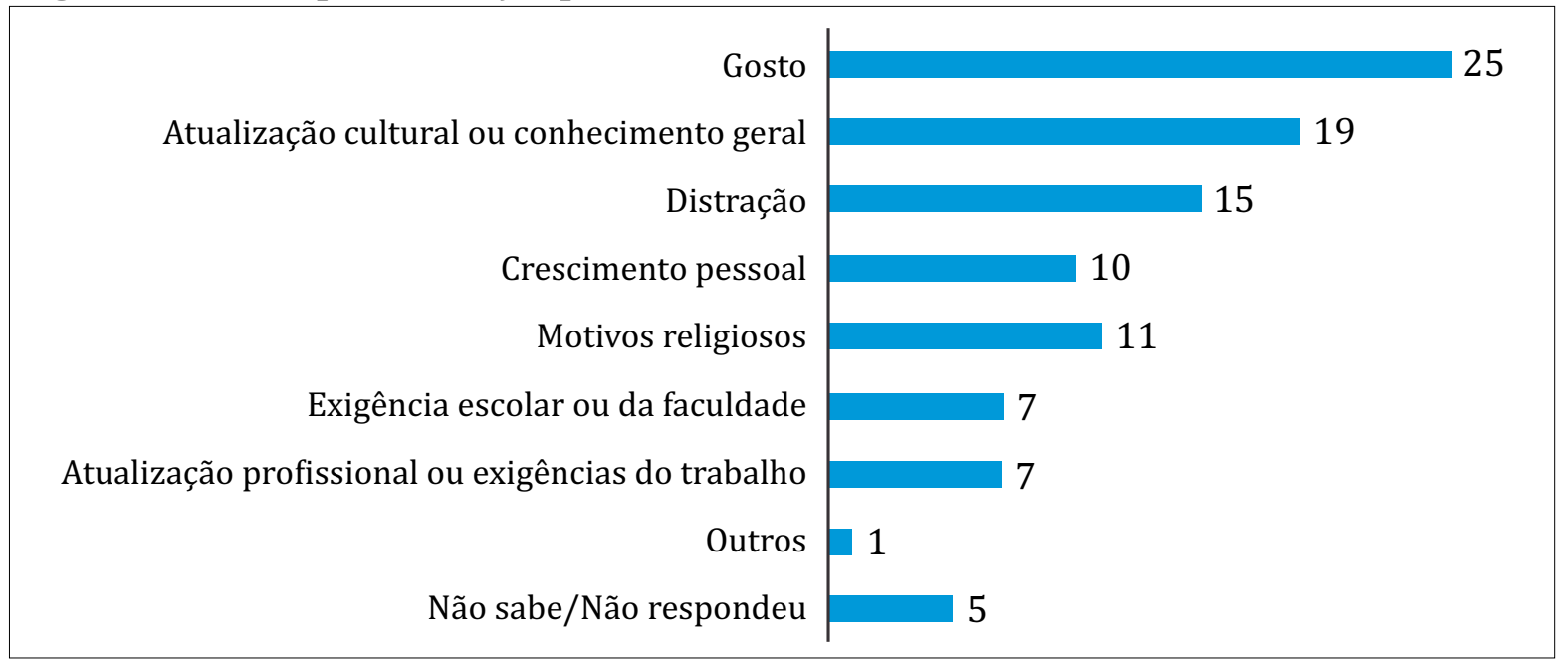

Fonte: Pesquisa Retratos da Leitura no Brasil. FAILLA (2016).

4 O capital cultural é entendido por Bourdieu (2012) como a aquisição e acúmulo de conhecimentos, formalizados de algum modo específico. Esta formalização pode se dar pela trajetória escolar, consubstanciada em um diploma ou certificado, mas também pode se dar pelo acesso à informação e conhecimento formatados nos suportes de livros, impressos em geral e, atualmente, também de publicações virtuais que tenham algum tipo de reconhecimento social. $\mathrm{Ou}$ seja, é a aquisição de conhecimento significativo e socialmente validado, por meio de sistemas tradicionais de creditação, como o escolar, o universitário, o profissional etc.

5 "O capital social é o conjunto de recursos atuais ou potenciais que estão ligados à posse de uma
Dentre estas respostas, a mais recorrente ("gosto") pode ser associada a uma prática social internalizada ou, pelo menos, percebida pelo sujeito como de seu interesse. A terceira e a quarta mais frequentes ("distração" e "crescimento pessoal”) também podem ser associadas aos mesmos tipos de motivações que a primeira. Isto se dá pelo fato de não ser destacada explicitamente nenhuma re-

rede durável de relações mais ou menos institucionalizadas de inter-conhecimento e de inter-reconhecimento (...)" (BOURDIEU, 2012, p. 67). 
ferência a recompensa externa à pessoa. Os retornos esperados são relacionados a questões da própria pessoa, e não medidos por algum tipo de diploma, promoção, ganho financeiro etc.

A resposta "atualização cultural ou conhecimento geral” pode tanto ser associada às motivações internalizadas, quanto pode estar refletindo motivações externas. Tal fato ocorre pela simples razão de que atualizar e obter informação tanto podem se referir à satisfação de interesses da própria pessoa, independentemente do meio onde vive, estuda ou trabalha. Mas também pode ser uma forma de introjetar uma cobrança real ou imaginária, sentida explicita ou implicitamente pela pessoa, frente ao meio em que vive, estuda ou trabalha. A perspectiva pragmática de obtenção de capitais cultural e social se manifesta nesta linha.

As respostas "exigência escolar ou da faculdade" e "atualização profissional ou exigência do trabalho" refletem motivações externas ainda reguladas por recompensas ou ausência de punição. O retorno está relacionado à forma como a instituição de ensino ou profissional irá reconhecer esta prática de leitura. Este é o tipo de motivação que não se sustenta, caso a regulação externa deixe de existir. Sair da escola ou da faculdade, ou mudar para outro emprego ou área que deixe de demandar as atualizações terão um impacto negativo sobre a prática de leitura, podendo até ocasionar sua eliminação.

A resposta "motivos religiosos" permanece dúbia. Há práticas de leitura religiosas que são impostas pelo grupo. Logo, para alcançar a recompensa da aceitação e do reconhecimento pelo grupo, a pessoa realiza a leitura demandada. Isto lhe dá um sentimento de pertencimento que vai ao encontro de sua necessidade básica de relacionamento. Este tipo de motivação externa dura enquanto o interesse na manutenção do vínculo com determinado grupo religioso perdurar. Por outro lado, há algumas religiões que incentivam a internalização do estímulo pela leitura, de tal forma que a progressão da pessoa nas práticas religiosas irá propiciar uma internalização progressiva da motivação para leitura. Ou seja, há casos desde motivação por regulação externa até casos de motivação internalizada. Ao citar como razão para a leitura os "motivos religiosos" a pessoa normalmente não está se referindo à motivação internalizada, devido ao fato de necessitar destacar este tipo de leitura, vinculando-o a determinada instância social que o legitima: a religião. A pessoa não lê porque sente algum tipo de satisfação pela própria leitura em si, mas porque é religiosamente impelida para tal. A satisfação está no cumprimento do rito e no atendimento do esperado pelo grupo religioso. Portanto, trata-se de uma motivação externa para leitura.

O relatório da pesquisa destaca que estas respostas variam com o nível de escolaridade, sendo mais recorrente a referência a "atualização cultural ou conhecimento geral" quanto mais escolarizada era a pessoa entrevistada. Enquanto as respostas referentes a "motivos religiosos" tiveram comportamento inverso, pois se reduziam com a elevação do grau de escolaridade. Isto demonstra a influência do meio sobre a prática de leitura. A elevação da escolaridade neste contexto não significa apenas maior acesso à informação e capacidade crítica, mas o pertencimento a outros grupos sociais, que significam e valoram as práticas de forma diferente dos grupos com menor escolaridade, principalmente no que se refere às práticas religiosas. Portanto, a convivência com os pares irá afetar a auto-regulação da motivação para ler, fazendo-a variar em algum grau com relação à valoração desta comunidade a respeito das práticas de leitura religiosa. 
É interessante constatar que os sujeitos entrevistados que apontavam o "gosto" e a "distração" como principais razões para ler eram maioria dentre os menos escolarizados. Enquanto para os mais escolarizados, as pressões do mercado de trabalho exercem uma indução para a leitura quase tão forte quanto à relativa a "gosto" e "distração". Vale destacar que a importância de regulação externa para a leitura por conta de exigência escolar, acadêmica e profissional é uma resposta que se mantém relativamente estável ao longo da escolaridade, mas que aumenta significativamente dentre aquelas pessoas com ensino superior. Esta motivação externa, portanto, está muito mais relacionada a determinado segmento social do que poderia se supor, caso esta variável apresentasse um comportamento linear quanto à escolaridade, crescendo proporcionalmente com sua elevação. Por outro lado, a superação das razões relacionadas à necessidade de conhecimento e crescimento pessoal frente às outras razões dentre os mais escolarizados pode ser reflexo da internalização da motivação para ler. As pessoas assumiram como suas as regulações externas sobre a importância de ler.
O peso da principal razão para ler apontada como motivos religiosos só é forte entre as pessoas equivalentes ao segmento considerado pelo IBGE como de analfabetos funcionais. Isto demonstra a importância deste tipo de regulação externa para a motivação para a leitura neste grupo. Isto demonstra o pouco peso desta razão dentre as motivações gerais, porém, quando se pensa em quais as motivações para ler por parte deste grupo e se observa, ao mesmo tempo, que o livro mais lido pela população brasileira permanece sendo a Bíblia, percebe-se a força indutora desta regulação externa sobre a geração de uma prática que não é usual nestes segmentos sociais. Ou seja, a regulação externa causada pela religião é capaz de motivar um grupo significativo de pessoas para a leitura, a despeito de seu habitus não contemplar este tipo de prática, tampouco de estimulá-lo ou até legitimá-lo - cabe aqui recordar as pesquisas que apontam para a reprovação de membros de um grupo quando "perdem" tempo com leitura, quando poderiam estar fazendo algo mais "produtivo" para o grupo (PETIT, 2008, 2009 e 2013).

Figura 2 - Principal motivação para ler um livro: por escolaridade.

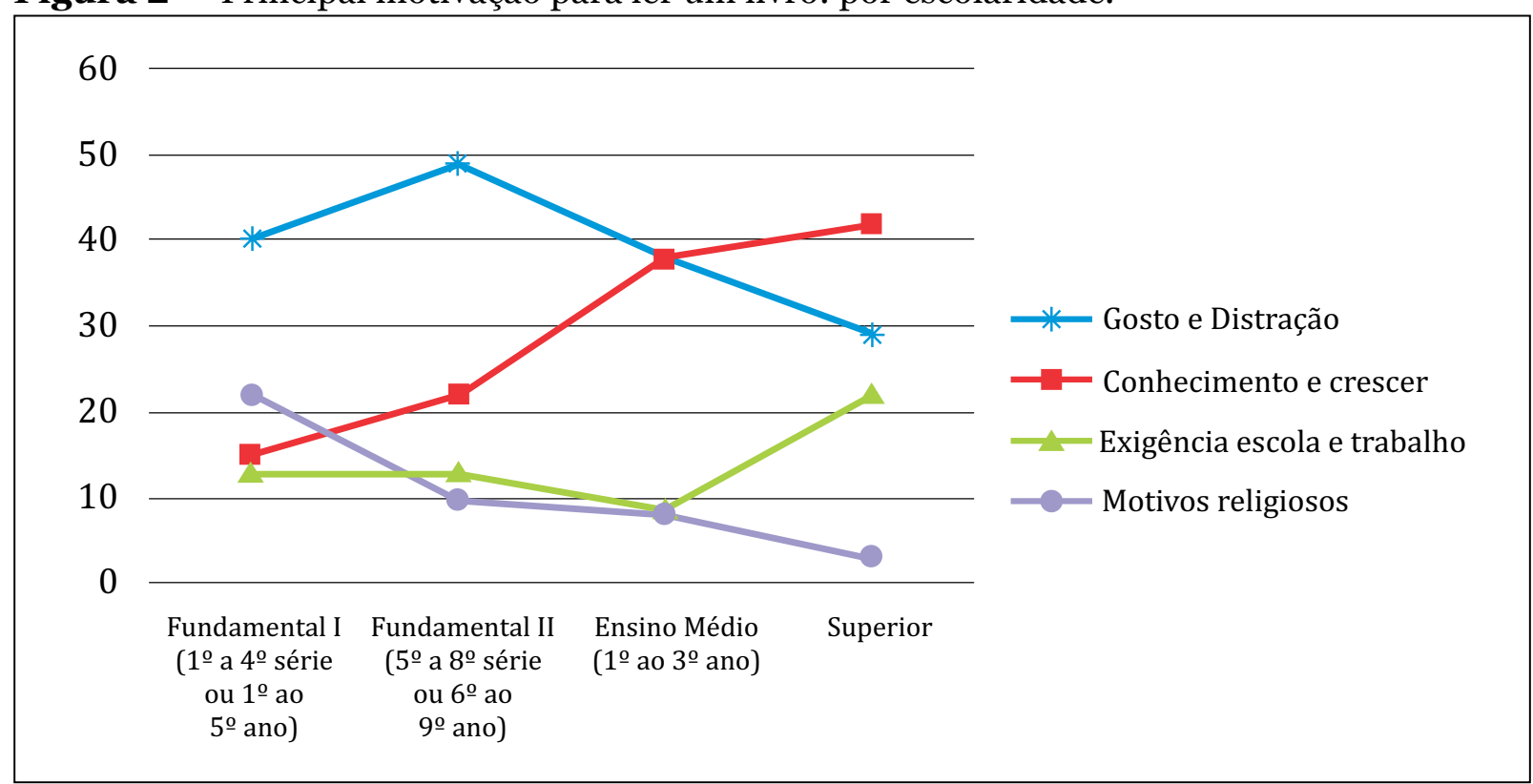

Fonte: Elaboração própria a partir da Pesquisa Retratos da Leitura no Brasil. FAILLA (2016). 
Em termos de relação com a faixa etária, as motivações internalizadas relativas a gosto e distração decrescem com a idade, voltando a crescer após a faixa de 30 a 39 anos. O comportamento inverso ocorre com aquelas relacionadas à aquisição de conhecimento e crescimento pessoal. Isto pode estar relacionado a pressões do mercado de trabalho, dado que a faixa etária onde ocorre a inflexão é exatamente a de 30 a 39 anos - o ápice da participação do indivíduo no mercado de trabalho. Antes desta faixa etária normalmente a pessoa está se qualificando e buscando posição no mercado de trabalho. Após esta faixa etária normalmente a pessoa já se estabilizou no mercado de trabalho, tanto no sentido de alcançou determinada posição quanto no referente a algum tipo de acomodação ou adaptação à realidade que enfrenta neste mercado. Isto é corroborado pelas respostas ligadas a exigência da escola e do trabalho, as quais são relativamente constantes até a faixa etária de 30 a 39 anos. Após esta faixa o decréscimo é evidente. Portanto, as pessoas percebem a necessidade da leitura para a educação e o trabalho, reagindo de forma positiva, quando afirmam ser este tipo de leitura para "atualização e crescimento", ou de forma negativa, ao associar esta demanda pela leitura como uma "exigência” institucional - da escola, universidade ou do trabalho.

Figura 3 - Principal motivação para ler um livro: por faixa etária.

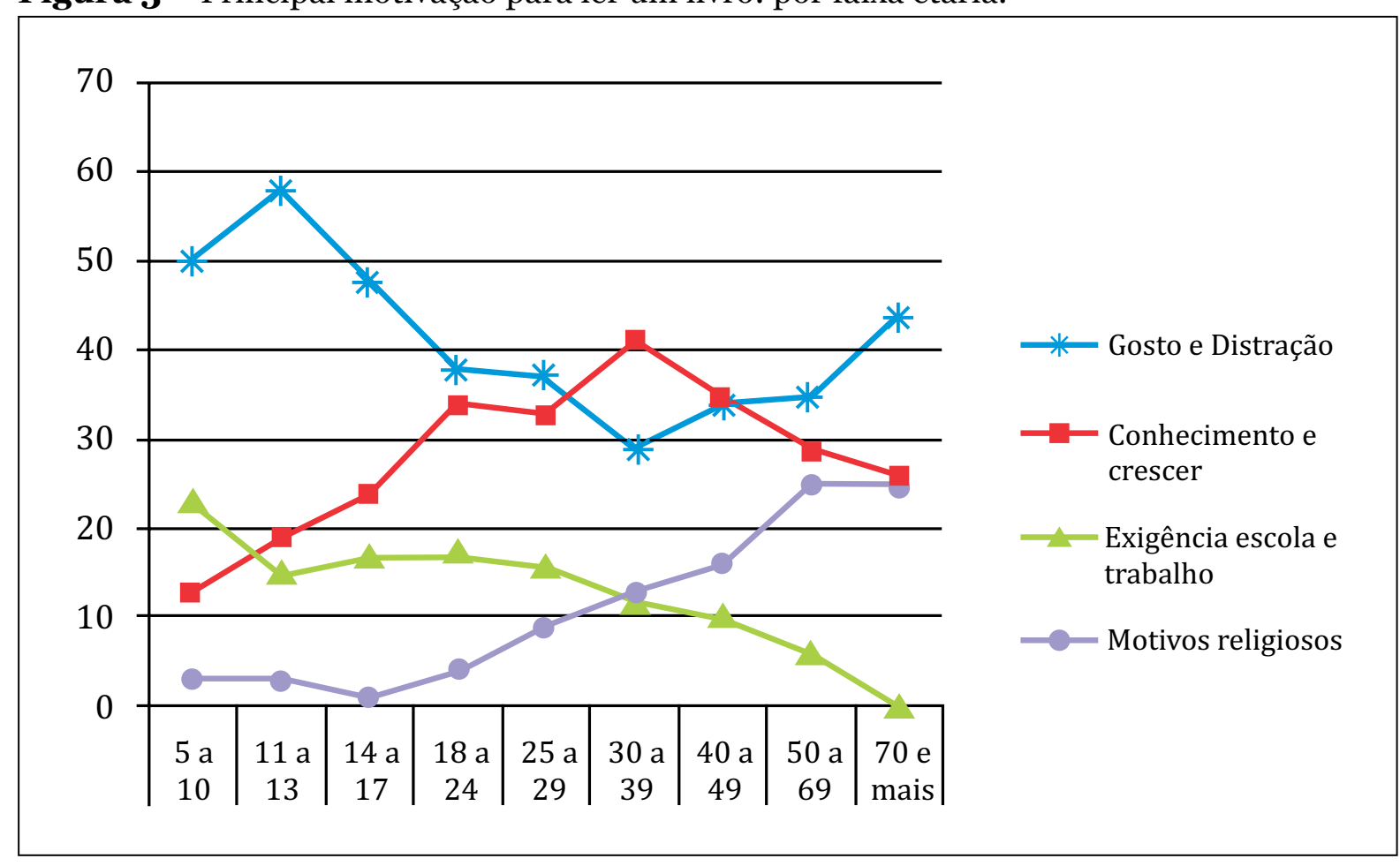

Fonte: Elaboração própria a partir da Pesquisa Retratos da Leitura no Brasil. FAILLA (2016).

Diferentemente de todas as outras, a resposta de leitura por motivos religiosos aumenta de uma forma constante desde a adolescência. Ela passa de menor frequência, para emparelhar com a segunda mais frequente na última faixa etária considerada. Isto pode indicar a instrumentalidade da leitura religiosa ao longo do ciclo da vida das pessoas. Quanto mais a idade avança, mais haveria estímulos externos para a prática da leitura por razões religiosas. A proximidade com o fim da vida poderia explicar isto. Todavia, o comportamento desta variável é muito linear e sua tendência tem uma infle- 
xão para cima na faixa etária entre 40 a 49 anos. Quando se atinge a faixa dos 50 a 69 anos há uma estabilização. O que demonstra que a preocupação com a questão religiosa, do ponto de vista da leitura, vai se elevando gradativamente ao longo da vida da pessoa, tomando maior impulso na meia idade e depois se estabilizando.

Caso se analise comparativamente as variáveis escolaridade e idade, percebe-se que a leitura por motivo religioso é significativamente maior entre os idosos do que entre as crianças e adolescentes. Considerando que a baixa escolaridade se concentra nestas faixas etárias, pode-se inferir que a leitura por motivos religiosos provavelmente seja maior dentre os idosos com baixa escolaridade. Este é o público tipicamente considerado pelo IBGE como analfabeto funcional. Fica facultada, então, a hipótese de que os analfabetos funcionais têm uma regulação externa que os motiva para a leitura. Considerando que os espaços religiosos são espaços de convivência e acolhida, bem como considerando o uso do tempo por parte dos idosos, seria possível verificar que a motivação para leitura neste caso estaria certamente relacionada à necessidade básica de relacionamento, a qual seria satisfeita pela relação de pertencimento ao grupo religioso e de aceitação pela identificação com a prática da leitura dos textos religiosos. Considerando que $25 \%$ de pessoas tanto entre 50 e 69 anos quanto com 70 anos ou mais responderam como principal razão para ler o motivo religioso e que apenas $41 \%$ e $27 \%$, respectivamente, são leitores, a motivação externa pela religião se torna um fator indutor importante para a leitura nestas faixas etárias.

\section{Considerações finais}

O presente artigo avança na compreensão do comportamento leitor de jovens e adultos no Brasil a partir dos aspectos sociais disponíveis na pesquisa de campo considerada, mais especificamente, a escolaridade e a faixa etária. Atinar para as variações entre os grupos sociais importa, mas entender como se dão as diferenças intragrupos também se mostra relevante. As disposições dentro de cada segmento social podem ser alteradas por exposição a estímulos externos, os quais podem provocar variações nas atitudes já disseminadas no grupo. O habitus é construído dinamicamente pelas relações entre os partícipes do grupo, sendo que estas mesmas relações podem alterar sua configuração ao longo do ciclo de vida dos sujeitos.

Logo, compreender como as dimensões sociais afetam a formatação das práticas de leitura envolve também entender como as influências externas ao grupo afetam a relação do sujeito com a cultura escrita. As próprias dimensões sociais não se dão no vácuo, elas interagem e se relacionam de tal forma que colocam em xeque análises estereotipadas de perfis de leitor e de não-leitor no Brasil. Estas interações não são estanques, mas variam ao longo da vida do próprio sujeito, ou seja, a localização social desse sujeito pode dar pistas sobre sua relação com a leitura, mas não define a priori tampouco irrevogavelmente a forma como ele se relaciona com a cultura escrita. A leitura não está dada, ela se (re)configura durante o ciclo de vida, dinamicamente.

Em uma sociedade dita do conhecimento, onde o acesso à informação se dá prioritariamente por meio da escrita/leitura, a base das relações apresenta um viés contratualista e as transações se tornam cada vez mais mecanizadas, virtuais e mediadas por máquinas, não ter domínio da leitura se torna um mecanismo estrutural de exclusão de direitos. Entender a dinâmica das motivações para leitura se torna, en- 
tão, estratégico para garantia de direitos, não apenas educacionais, mas culturais e outros cuja fruição passa igualmente por uma determinada relação com a cultura escrita. $\mathrm{O}$ acesso a estes direitos deve ser garantido pelo Estado, o que demandará políticas de promoção do letramento como mecanismo estruturante de um sistema de garantia de direitos que seja realmente republicano e democrático. $\mathrm{O}$ analfabetismo não pode mais ser tido como um ranço que irá acabar com a universalização da escola e com a mudança geracional. O problema tem se reconfigurado, colocando em outro patamar a exclusão social pelas barreiras à entrada ou pela qualidade regulada do acesso à cultura escrita.

Neste contexto, a Pesquisa Retratos da Leitura no Brasil se revela uma rica fonte de informações para investigações que aprofundem as análises sobre as dimensões sociais da motivação para leitura de jovens e adultos, atentando para as interações entre as variáveis consideradas. A exploração sobre como as construções sociais das motivações para leitura são internalizadas pelos sujeitos e tomadas como "naturais" precisa avançar, a fim de que se tenha maior clareza sobre a dinâmica social do alfabetismo e, em especial, da relação com a cultura escrita por parte dos jovens e adultos no Brasil do século XXI.

\section{Referências}

AMORIM, G. Retratos da leitura no Brasil. São Paulo: Instituto Pró-Livro e Imprensa Oficial do Estado de São Paulo, 2008.

BOURDIEU, P. A Distinção: crítica social do julgamento. São Paulo: EDUSP; PortoAlegre: Zouk, 2008.

A Economia das Trocas Simbólicas. $6^{\mathrm{a}}$ ed. São Paulo: Perspectiva,2007.

A institucionalização da anomia.
In: O Poder Simbólico. Lisboa, Portugal: Edições 70, 2014.

. Escritos de educação. NOGUEIRA, M. A. e CATANI, A. (orgs). Petrópolis: Vozes, 2012.

.Pierre Bourdieu: Sociologia. Renato Ortiz (org.). São Paulo: Ática, 1983.

Questões de Sociologia. Lisboa: Fim de Século, 2003.

.; e PASSERON, J. C. A reprodução: elementos para uma teoria do sistema de ensino. 3. ed. Petrópolis: Vozes, 2008.

.; e Os herdeiros: os estudantes e a cultura. Florianópolis: Editora UFSC, 2013 .

FAILla, Z. (Org). Retratos da leitura no Brasil 3. São Paulo: Instituto Pró-Livro e Imprensa Oficial do Estado de São Paulo, 2012.

Retratos da leitura no Brasil 4. Rio de Janeiro: Sextante, 2016.

FERRARO (FERRARI), A. Analfabetismo no Brasil: tendência secular eavanços recentes. Resultados preliminares. Cadernos de Pesquisa, São Paulo, n. 52, fev.1985, p. 35-49.

FERRARO, A. História inacabada do analfabetismo no Brasil. São Paulo: Cortez, 2009.

.; KREIDLOW, D. Analfabetismo no Brasil: configuração e gênese das desigualdades regionais. Educação \& Realidade, v. 29, 2, jul./ dez. 2004. p. 179-200.

FLEURY, L. Sociologia da cultura e das práticas culturais. São Paulo: Editora SENAC São Paulo, 2009.

KALMAN, J. Cultura escrita - e la prendizaje de lalectura y la escritura para su uso en la vida cotidiana. Decisio. Invierno, 2003a.p. 3-9.

. El acceso a la cultura escrita: la participación social y la apropriación de conocimientos en eventos cotidianos de lectura y escritura. Revista Mexicana de Investigación Educativa, Consejo Mexicano de Investigación Educativa, v. VIII, n. 17, enero-abril, 2003b. p. 37-66.

PEREIRA, M. H. F.; e SARTI, F. M. A leitura entre táticas e estratégias? Consumo cultural e práticas epistolares. História da Educação, AS- 
PHE/FaE/UFPel, Pelotas, v. 14, n. 31. mai/ago 2010. p. 195-217.

PETIT, M. A arte de ler ou como resistir à adversidade. São Paulo: Editora 34, 2009.

Leituras: do espaço íntimo ao espaço público. São Paulo: Editora 34, 2013.

Os Jovens e a Leitura - uma nova perspectiva. São Paulo: Editora 34, 2008.

RYAN, R. M.; and DECI, E. L. Intrinsic and extrinsic motivations: classic definitions and new directions. Contemporary Educational Psychology, n. 25, 2000. p. 54-67.

SETTON, M. G. J. A teoria do habitus em Pierre Bourdieu: uma leitura contemporânea. Revista Brasileira de Educação, n. 20. maio/jun/jul/ ago, 2002. p. 60-70.

TAKALOO, N. M., e AHMADI, M. R. The effect of learners' motivation on their reading comprehension skill: a literature review. Internatio- nal Journal of Research in English Education. Online Published: September 20, 2017. p. 10-21. Disponível em: http://ijreeonline.com/files/ site1/user_files_68bcd6/m ammadrezaahmadi-A-10-25-2-efae737.pdf. Acesso em o4 dez 2017.

VARGAS, P. G., e GOMES, M. F. C. Aprendizagem e desenvolvimento de jovens e adultos: novas práticas sociais, novos sentidos. Educação e Pesquisa, São Paulo, v. 39, n. 2, abr./jun. 2013. p. 449-463.

WACQUANT, L. Esclarecer o Habitus. Educação \& Linguagem, Ano 10, nº 16. jul-dez, 2007. p. 63-71.

. Mapear o campo artístico. Sociologia, problemas e práticas, n. 48, 2005. p. 117-123.

Recebido em: 11/11/2018 Aprovado em: 13/12/2018 